\title{
Pengaruh Kompetensi terhadap Kepuasan Kerja dan Work Engagement Karyawan UKM Kluster Hasil Pengolahan Perikanan di Bogor
}

\section{The Impact of Competence on Job Satisfaction and Work Engagement of Fish Processing SMEs Emloyee in Bogor}

\author{
Arvina Utami ${ }^{1}$, Anggraini Sukmawati ${ }^{1 *}$ \\ ${ }^{1}$ Departemen Manajemen, Fakultas Ekonomi dan Manajemen, IPB Kampus Dramaga Bogor 16680
}

\begin{abstract}
The number of SMEs and amount of processed fish products in the city of Bogor is potential for the development of fish processing SMEs. SMEs need employees who are satisfied with their job and engaged with their work to maximize the development of their potential. The purpose of this study was to analyze the effects of competence and compensation on the job satisfaction and work engagement of employees of fish processing SMEs in Bogor. The sampling method used was a non-probability sampling technique, namely the census technique. The data processing and analysis methods were validity and reliability testing using SPSS, descriptive analysis, and Structural Equation Modeling (SEM) using SmartPLS. The descriptive analysis results showed the perceptions of employees towards competence, compensation, job satisfaction and work engagement.The SEM results show that job satisfaction was affected by competence and compensation. Work engagement was affected by competence and job satisfaction but it was not affected by compensation.
\end{abstract}

Keywords: competence, job satisfaction, Small and Medium Enterprise (SME), Structural Equation Modeling (SEM), work engagement

\section{ABSTRAK}

Jumlah UKM dan jumlah produk hasil olahan perikanan yang besar di wilayah Kota Bogor menjadikan UKM kluster hasil pengolahan perikanan potensial untuk dikembangkan. UKM memerlukan karyawan yang memiliki kepuasan kerja dan work engagement yang baik untuk dapat mengembangkan potensinya secara maksimal. Tujuan penelitian ini adalah menganalisis pengaruh kompetensi dan kompensasi terhadap kepuasan kerja dan work engagement karyawan UMKM kluster pengolahan hasil perikanan Kota Bogor. Metode pengambilan sampel yang digunakan adalah non-probability sampling dengan teknik sensus. Metode analisis data yang digunakan yaitu uji validitas dan reliabilitas dengan program SPSS, analisis deskriptif, dan Structural Equation Modeling (SEM) dengan program SmartPLS. Hasil analisis deskriptif menunjukkan persepsi karyawan terhadap kompetensi, kompensasi, kepuasan kerja dan work engagement. Hasil analisis SEM menunjukkan bahwa kepuasan kerja dipengaruhi oleh kompetensi dan kompensasi. Work engagement dipengaruhi oleh kompetensi dan kepuasan kerja tetapi tidak dipengaruhi oleh kompensasi.

Kata Kunci: kepuasan kerja, kompetensi, Structural Equation Modeling (SEM), Usaha Kecil dan Menengah (UKM), work engagement

*Corresponding author

Alamat e-mail: anggrainism@gmail.com 


\section{PENDAHULUAN}

Masyarakat Ekonomi ASEAN (MEA) atau ASEAN Economic Community (AEC) mulai diberlakukan di Indonesia pada tahun 2016. Hal ini berarti bahwa persaingan antara Indonesia dengan negara-negara anggota ASEAN lain akan semakin meningkat dalam segala aspek. Percepatan pembangunan dan penguatan ekonomi harus senantiasa dilakukan. Salah satu hal yang perlu difokuskan yaitu penguatan kemampuan Usaha Kecil dan Menengah (UKM) dalam mengembangkan potensi yang dimilikinya agar daya saing usaha-usaha kecil dan menengah yang ada dapat meningkat.

Tahun 2013 Indonesia memiliki 57 juta UMKM yang menyediakan lapangan pekerjaan bagi sekitar 114 juta orang (Kemenkop 2015). Lebih dari 95\% badan usaha di Indonesia berbentuk UKM. UKM merupakan penyerap tenaga kerja yang paling besar (Gryseels et al. 2015). Jumlah tenaga kerja yang diserap UMKM sebesar 97,30\% persen dari total penyerapan tenaga kerja secara nasional. Kontribusi sektor UMKM terhadap pertumbuhan ekonomi nasional juga sangat signifikan yaitu menyumbang 58,92\% terhadap Produk Domestik Bruto (PDB) (OJK 2016).

Jawa Barat memberikan kontribusi PDB terbesar ketiga di Indonesia yaitu sebesar $14,33 \%$ terhadap PDB nasional (Pemprov Jabar 2014). Jumlah UMKM yang ada di Jawa Barat juga terus meningkat. Peningkatan jumlah UMKM di Jawa Barat selama tahun 2010-2012 dapat dilihat pada Tabel 1.

Tabel 1. Perkembangan unit usaha Jawa Barat tahun 2010-2012

\begin{tabular}{|c|c|c|c|c|c|}
\hline \multirow[t]{2}{*}{ No } & \multirow[t]{2}{*}{ Unit Usaha } & \multicolumn{3}{|c|}{ Tahun } & \multirow[t]{2}{*}{$\begin{array}{c}\text { Laju } \\
\text { Pertumbuhan } \\
\text { Rata-rata }\end{array}$} \\
\hline & & 2010 & 2011 & 2012 & \\
\hline 1 & Usaha Mikro & 8.616 .294 & 8.626 .671 & 9.042 .519 & $2,47 \%$ \\
\hline 2 & Usaha Kecil & 106.591 & 116.062 & 115.749 & $4,31 \%$ \\
\hline 3 & Usaha Menengah & 7.408 & 8.818 & 8.235 & $6,21 \%$ \\
\hline \multirow[t]{2}{*}{4} & Usaha Besar & 1.536 & 1.728 & 1.853 & $9,87 \%$ \\
\hline & Total Usaha & 8.731 .829 & 8.752 .642 & 9.168 .356 & $2,48 \%$ \\
\hline
\end{tabular}

Sumber: Dinas Koperasi dan Usaha Kecil Menengah Provinsi Jawa Barat (2013)

Kota Bogor merupakan salah satu kota yang berada di Provinsi Jawa Barat. Kota ini merupakan kota yang berkembang apabila dilihat dari segi perekonomian. Kemajuan ekonomi Kota Bogor tidak lepas dari peranan berbagai UMKM yang membantu kemajuan ekonomi kota dengan berbagai macam produk yang dihasilkan. Perkembangan jumlah UMKM di Kota Bogor dapat dilihat pada Tabel 2.

Tabel 2. Pertumbuhan jumlah unit UMKM Kota Bogor tahun 2011-2015

\begin{tabular}{lcccccc}
\hline Kecamatan & 2011 & 2012 & 2013 & 2014 & 2015 & $\begin{array}{c}\text { Laju Pertumbuhan } \\
\text { Rata-rata }\end{array}$ \\
\hline Bogor Timur & 931 & 955 & 1.005 & 1.055 & 1.080 & $3,79 \%$ \\
Bogor Barat & 2.301 & 2.498 & 2.794 & 3.085 & 3.146 & $8,20 \%$ \\
Bogor Selatan & 2.208 & 2.237 & 2.275 & 2.313 & 2.338 & $1,44 \%$ \\
Bogor Utara & 1.734 & 1.750 & 1.772 & 1.794 & 1.817 & $1,18 \%$ \\
Tanah Sareal & 1.103 & 1.147 & 1.151 & 1.199 & 1.218 & $2,52 \%$ \\
Bogor Tengah & 1.349 & 1.417 & 1.506 & 1.595 & 1.621 & $4,71 \%$ \\
\hline Jumlah & 9.626 & 10.004 & 10.503 & 11.041 & 11.220 & $3,92 \%$ \\
\hline
\end{tabular}

Jurnal Manajemen dan Organisasi (JMO),

Vol. 9, No. 1, April 2018, Hal. 10-21

Sumber: Dinas Koperasi dan UMKM Kota Bogor, data diolah (2016) 
Salah satu kluster UMKM yang ada di Kota Bogor yaitu UMKM jenis kluster agro. UMKM agro Kota Bogor banyak bergerak di bidang industri pengolahan. Contohnya yaitu UMKM pengolahan hasil perikanan. UMKM pada sektor industri pengolahan ini mampu menyerap tenaga kerja. Akan tetapi rendahnya produktivitas masih menjadi permasalahan UMKM untuk berkembang (Kemenkop 2015).

Banyaknya UMKM yang ada belum diiringi peningkatan kinerja yang signifikan. Salah satu hal yang perlu diperhatikan dalam menilai produktivitas UMKM yaitu aspek human capital atau para karyawan. Untuk meningkatkan kinerja suatu UMKM dan membuat karyawan tetap loyal, dibutuhkan karyawan yang berdedikasi terhadap pekerjaannya dan memiliki suatu keterikatan emosional dengan pekerjaannya. Keterikatan ini disebut dengan work engagement atau keterlekatan kerja. Work engagement dapat dipengaruhi oleh banyak faktor seperti kompetensi, kompensasi dan kepuasan kerja.

Kompetensi pekerjaan merupakan perilaku yang dapat diobservasi dan diukur yang memuat suatu bagian pekerjaan (Dessler 2010). Kompetensi merupakan faktor yang penting karena dipercaya sebagai faktor kunci penentu bagi seseorang dalam menghasilkan kinerja yang baik (Rivai dan Sagala 2009). Kompensasi yaitu pemberian balas jasa yang diberikan baik secara langsung maupun tidak langsung kepada seseorang atas kinerjanya. Kompensasi yang diberikan berpengaruh besar terhadap semangat dan kegairahan kerja para pegawai (Kadarisman 2012). Kepuasan kerja dapat dikatakan merupakan evaluasi yang menggambarkan seseorang atas perasaan sikapnya senang atau tidak senang, puas atau tidak puas dalam bekerja. Kepuasan kerja penting untuk diperhatikan karena dapat menciptakan perilaku yang mempengaruhi fungsi-fungsi perusahaan (Rivai dan Sagala 2009). Work engagement merupakan hubungan antara karyawan dengan pekerjaannya (Schaufeli dan Salanova 2011). Engagement merupakan sesuatu yang penting untuk sebuah organisasi. Bahkan, banyak yang berpendapat bahwa engagement merupakan faktor kunci keberhasilan dan keunggulan kompetitif suatu organisasi (Saks dan Gruman 2014).

Sebagian UMKM kluster hasil pengolahan perikanan Kota Bogor berada di bawah binaan pemerintah Kota Bogor. Beberapa contoh program untuk UMKM kluster hasil pengolahan perikanan ini yaitu program pelatihan pembuatan berbagai macam produk hasil olahan ikan, program pelatihan penyuluh perikanan swadaya, pembuatan label pada kemasan, acara Gerakan Makan (Gemar) Ikan, bazaar, serta seminar. Program-program ini diharapkan akan meningkatkan kemampuan UMKM kluster hasil pengolahan perikanan dalam hal kompetensi dan kompensasi. Pengetahuan yang didapatkan oleh karyawan UMKM tersebut dapat meningkatkan keterampilannya dalam bekerja sehingga kualitas dan variasi produk hasil olahan ikan UMKM dapat meningkat. Karyawan UMKM juga bisa meningkat pendapatannya apabila UMKM dapat menjual produk berkualitas yang mampu bersaing di pasaran. Meningkatnya kompetensi dan kompensasi akan meningkatkan kepuasan kerja. Kepuasan kerja karyawan erat kaitannya dengan work engagement karyawan.

Untuk mengetahui bagaimana pengaruh faktor-faktor tersebut pada karyawan yang Jurnal Manajemen dan Organisasi (JMO), Vol. 9, No. 1, April 2018, Hal. 10-21 bekerja di UMKM kluster pengolahan hasil perikanan, perlu diketahui apakah faktor kompetensi, kompensasi dan kepuasan kerja berpengaruh terhadap work engagement seorang karyawan dan seperti apa pengaruh tersebut. Tujuan penelitian ini adalah: (1) Menganalisis persepsi karyawan terhadap kompetensi, kompensasi, kepuasan kerja, dan work engagement karyawan UMKM kluster hasil pengolahan perikanan Kota Bogor. (2) Menganalisis pengaruh kompetensi dan kompensasi terhadap kepuasan kerja karyawan UMKM kluster hasil pengolahan perikanan Kota Bogor. (3) Menganalisis pengaruh kompetensi, kompensasi dan kepuasan kerja terhadap work engagement karyawan di UMKM kluster hasil pengolahan perikanan Kota Bogor. 


\section{METODE PENELITIAN}

Usaha kecil dan menengah merupakan usaha yang menopang sektor perekonomian Indonesia. Adanya berbagai kemajuan dan perubahan kebijakan seperti diberlakukannya MEA membuat peranan UMKM semakin penting bagi perekonomian nasional. UMKM pengolahan hasil perikanan masih memiliki potensi untuk lebih dikembangkan lagi. Potensi ini dapat dilihat salah satunya dari jumlah produk perikanan yang masuk ke Kota Bogor sebesar 13,42 ton per hari. Sebanyak 12,46 ton mampu diolah per tahunnya (Rahmawati 2014). Pengembangan potensi ini memerlukan peningkatan kapasitas SDM pada masing-masing UMKM. Untuk itu, penelitian ini dilakukan guna melihat bagaimana pengaruh kompetensi dan kompensasi pada kepuasan kerja dan work engagement para karyawan UMKM.

Indikator kompetensi diukur dengan menggunakan teori Spencer dan Spencer (1994) dalam Hutapea dan Thoha (2008) yang terdiri dari: pengetahuan, keterampilan, konsep diri, ciri diri, dan motif. Indikator kompensasi diukur dengan menggunakan teori yang dikemukakan Simamora (2004). Teori ini menyatakan bahwa kompensasi dapat dibagi menjadi 2 jenis, yaitu kompensasi finansial dan non-finansial. Kompensasi finansial mencakup gaji, upah, bonus, komisi, dan hari besar. Kompensasi non-finansial mencakup pengakuan dan rasa pencapaian yang termasuk ke dalam pekerjaan; kerabat kerja yang menyenangkan dan lingkungan kerja yang nyaman. Indikator kepuasan kerja diukur menggunakan teori Rivai dan Sagala (2009) terdiri dari: isi pekerjaan, supervisi, organisasi dan manajemen, kesempatan untuk maju, gaji dan keuntungan finansial lain, rekan kerja, serta kondisi pekerjaan. Indikator work engagement diukur menggunakan teori Schaufeli, Bakker dan Salanova (2006) yang terdiri dari: vigor (kekuatan), dedication (dedikasi) dan absorption (absorpsi). Uji validitas dan reliabilitas dilakukan menggunakan program SPSS. Persepsi karyawan terhadap kompetensi, kompensasi, kepuasan kerja dan work engagement diukur menggunakan analisis deskriptif. Pengaruh yang terjadi dianalisis dengan menggunakan Structural Equation Modeling (SEM) metode Partial Least Square (PLS).

Hasilnya menunjukkan apakah masing-masing variabel memiliki pengaruh atau tidak pada work engagement pekerja UMKM pengolahan hasil perikanan Kota Bogor. Hasil persepsi dan pengaruh yang dianalisis dapat menjadi implikasi manajerial dan rekomendasi bagi UMKM agar dapat meningkatkan work engagement karyawannya dengan lebih efisien. Kerangka pemikiran penelitian ini dapat dilihat pada Gambar 1. 
Jurnal Manajemen dan Organisasi (JMO),

Vol. 9, No. 1, April 2018, Hal. 10-21

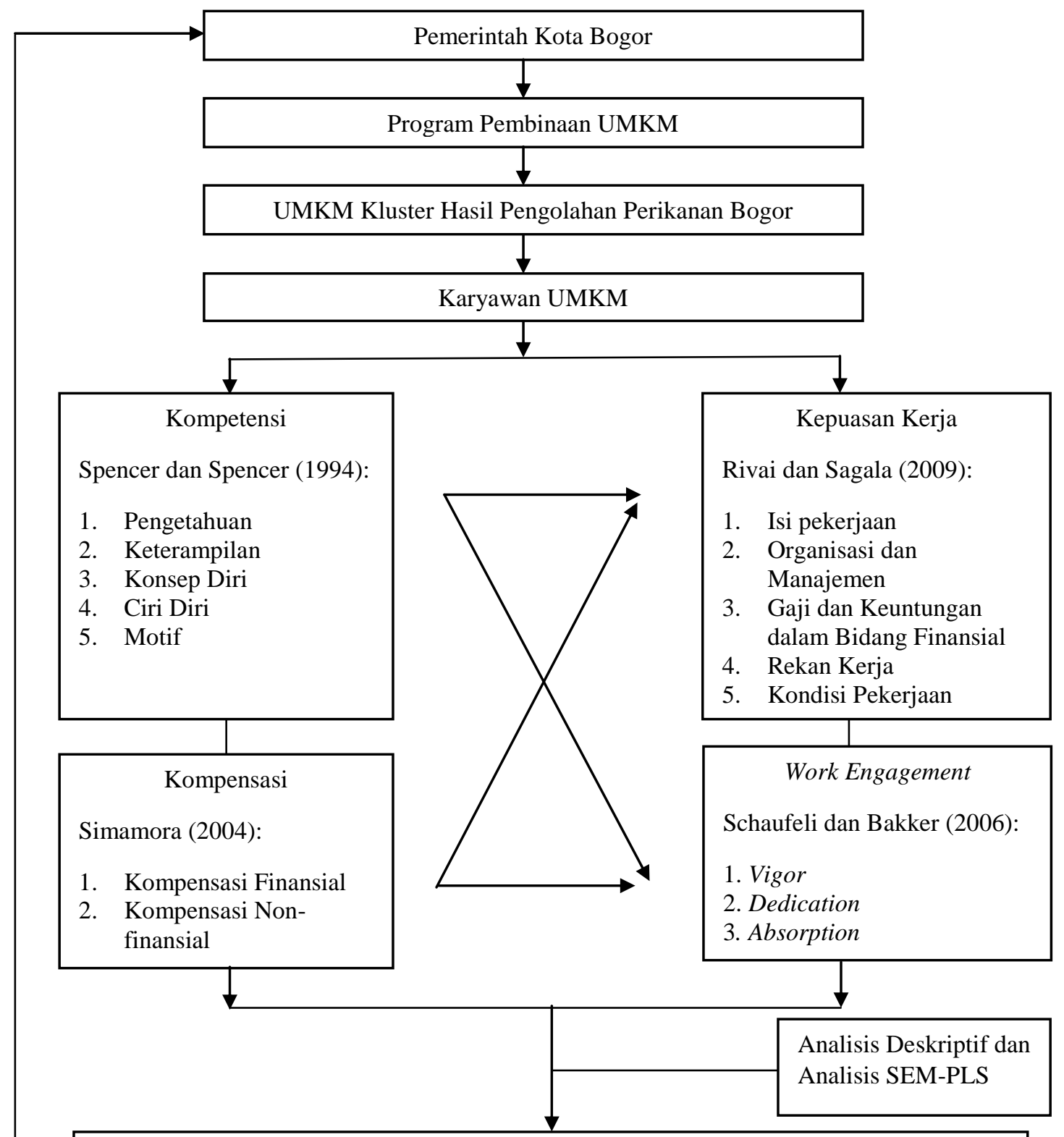

Pengaruh Kompetensi dan Kompensasi terhadap Kepuasan Kerja dan Work Engagement

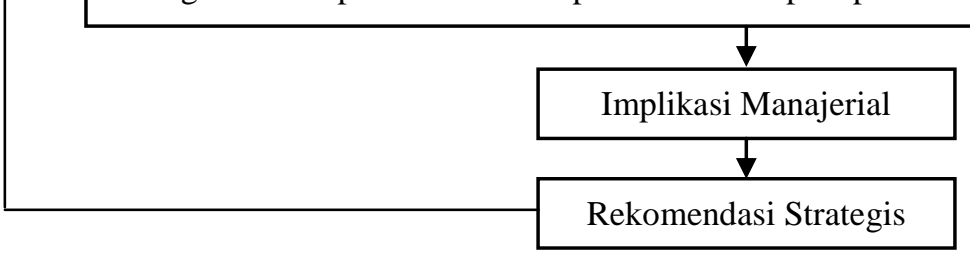

Gambar 1. Kerangka pemikiran penelitian

Penelitian ini dilakukan di UMKM hasil pengolahan perikanan yang berada di Kota Bogor, Jawa Barat dan dilaksanakan pada bulan Februari - Oktober 2016. Penentuan lokasi penelitian dilakukan secara sengaja (purposive) berdasarkan pertimbangan bahwa Bogor merupakan daerah yang memiliki potensi tinggi dalam pengolahan hasil perikanan. Jenis data yang digunakan dalam penelitian ini terdiri dari data primer dan data sekunder. Data primer diperoleh dengan melakukan wawancara dan penyebaran kuesioner yang diisi oleh seluruh karyawan yang bekerja pada UMKM kluster hasil pengolahan perikanan Kota Bogor sebagai responden. Kuesioner menggunakan pertanyaan tertutup dengan skala likert. Metode penentuan sampel yang digunakan untuk menentukan responden pada penelitian ini yaitu sampling jenuh. 
Sampel yang dipilih yaitu 58 karyawan UMKM kluster pengolahan hasil perikanan yang berada di bawah naungan dan binaan Dinas Pertanian Kota Bogor. Lokasi UMKM tersebar di wilayah Kota Bogor, yaitu di kecamatan Bogor Utara, Bogor Timur, Bogor Selatan, dan Bogor Barat. Produk yang dihasilkan yaitu berbagai macam makanan hasil olahan ikan. Contohnya yaitu ikan pindang, dendeng belut, dendeng nila, bakso ikan, ikan balita, serta nugget ikan. Selain data primer, digunakan pula data sekunder dari berbagai literatur berupa buku, jurnal, serta skripsi yang relevan dengan penelitian ini. Data sekunder juga diperoleh dari berbagai laporan dan dokumen yang berkaitan dengan topik penelitian ini.

\section{HASIL DAN PEMBAHASAN}

\section{Persepsi Karyawan terhadap Kompetensi, Kompensasi, Kepuasan Kerja dan Work Engagement}

Persepsi karyawan terhadap kompetensi, kompensasi, kepuasan kerja serta work engagement diukur menggunakan kecenderungan modus. Persepsi karyawan terhadap indikatorindikator kompetensi yang ada pada UMKM kluster hasil pengolahan perikanan Kota Bogor mayoritas menunjukkan pendapat setuju. Indikator yang paling banyak menunjukkan pendapat setuju yaitu bahwa karyawan setuju pengetahuan karyawan bertambah selama karyawan tersebut bekerja dengan frekuensi nilai sebesar 75,9\%. Persepsi karyawan terhadap indikatorindikator kompensasi yang ada pada UMKM kluster hasil pengolahan perikanan Kota Bogor mayoritas menunjukkan pendapat setuju. Indikator yang paling banyak menunjukkan pendapat setuju yaitu penghargaan dan pengakuan yang dirasakan oleh karyawan dengan frekuensi nilai sebesar $81 \%$. Persepsi karyawan terhadap indikator-indikator kepuasan kerja yang ada pada UMKM kluster hasil pengolahan perikanan Kota Bogor mayoritas menunjukkan pendapat setuju. Indikator yang paling banyak menunjukkan pendapat setuju yaitu bahwa karyawan mengerjakan tugas sesuai keahliannya dengan frekuensi nilai sebesar $82,75 \%$. Indikator yang juga paling banyak menunjukkan pendapat setuju yaitu bahwa gaji yang didapatkan karyawan sesuai dengan tanggung jawab yang dilaksanakan dengan frekuensi nilai sebesar $82,75 \%$. Persepsi karyawan terhadap indikator-indikator work engagement yang ada pada UMKM kluster hasil pengolahan perikanan Kota Bogor mayoritas menunjukkan pendapat setuju. Indikator yang paling banyak menunjukkan pendapat setuju yaitu karyawan merasa senang saat produktif dalam bekerja dengan frekuensi nilai sebesar $82,75 \%$.

\section{Hasil Analisis Structural Equation Modeling (SEM)}

Structural Equation Modeling (SEM) yaitu teknik analisis multivariat yang mampu menganalisis variabel indikator, variabel laten, dan kekeliruan pengukuran variabel, yang pada alat analisis statistika lainnya belum ada (Umar 2013). Structural Equation Modeling mampu menguji model penelitian yang kompleks secara simultan dan bekerja dengan ukuran sampel yang kecil. PLS memiliki dua model indikator, yaitu model formatif dan model reflektif. Model formatif memiliki karakteristik bahwa perubahan dalam indikator akan menyebabkan perubahan dalam konstruk (Wiyono 2011). Menghilangkan satu indikator akan berakibat perubahan makna dari konstruk (Ghozali 2008). Model refleksif memiliki karakteristik internal konsistensi oleh karena semua ukuran indikator diasumsikan semuanya valid mengukur suatu konstruk, sehingga dua ukuran indikator yang sama reliabilitasnya dapat saling dipertukarkan. Walaupun reliabilitas (cronbach alpha) suatu konstruk akan rendah jika hanya ada sedikit indikator, tetapi validitas suatu konstruk tidak akan berubah jika satu indikator dihilangkan.

Metode SEM memiliki 2 macam spesifikasi model, yaitu Model Pengukuran (Outer Model) dan Model Struktural (Inner Model). Model yang pertama yaitu Model Pengukuran (Outer Model). Pada tahap ini dilakukan evaluasi convergent validity, discriminant validity, dan uji reliabilitas. Pada model yang kedua yaitu Model Struktural (Inner Model), dilakukan pengujian model konstruk dan uji hipotesis. 


\section{Convergent Validity}

Convergent validity dapat dilihat dari nilai loading factor dan nilai Average Variance Extracted (AVE). Convergent validity dari measurement model dengan indikator reflektif dapat dilihat dari korelasi antara score item/indicator dengan score konstruknya. Indikator individu dianggap reliable jika memiliki nilai korelasi di atas 0,70, namun loading 0,50-0,60 masih dapat diterima (Ghozali 2008). Output loading factor pada penelitian dapat dilihat pada Gambar 2.

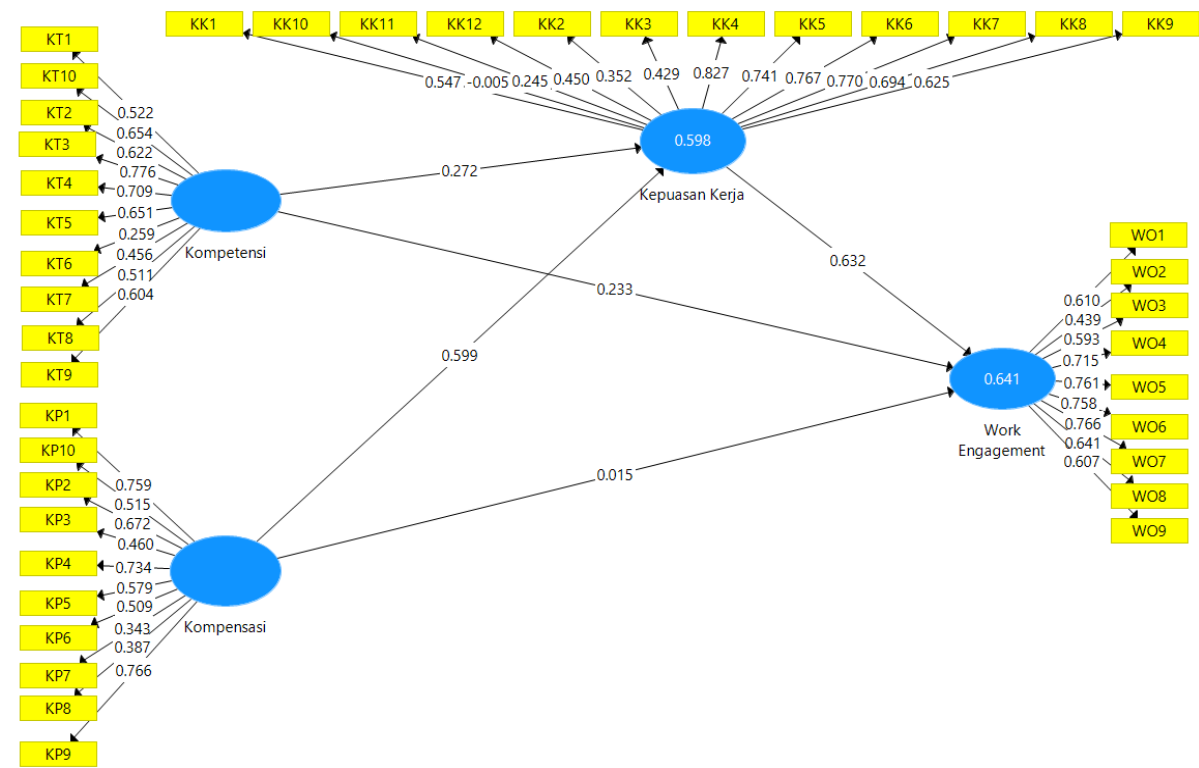

Gambar 2.Outer model awal

Sumber: Data diolah (2016)

Pada Gambar 2 di atas dapat dilihat bahwa beberapa indikator memiliki nilai loading factor kurang dari 0,50. Maka dilakukan penghapusan terhadap indikator tersebut dan dilakukan run ulang sampai semua indikatornya mempunyai nilai loading factor lebih dari 0,50. Setelah dilakukan run ulang, model baru yang dihasilkan sebagai berikut.

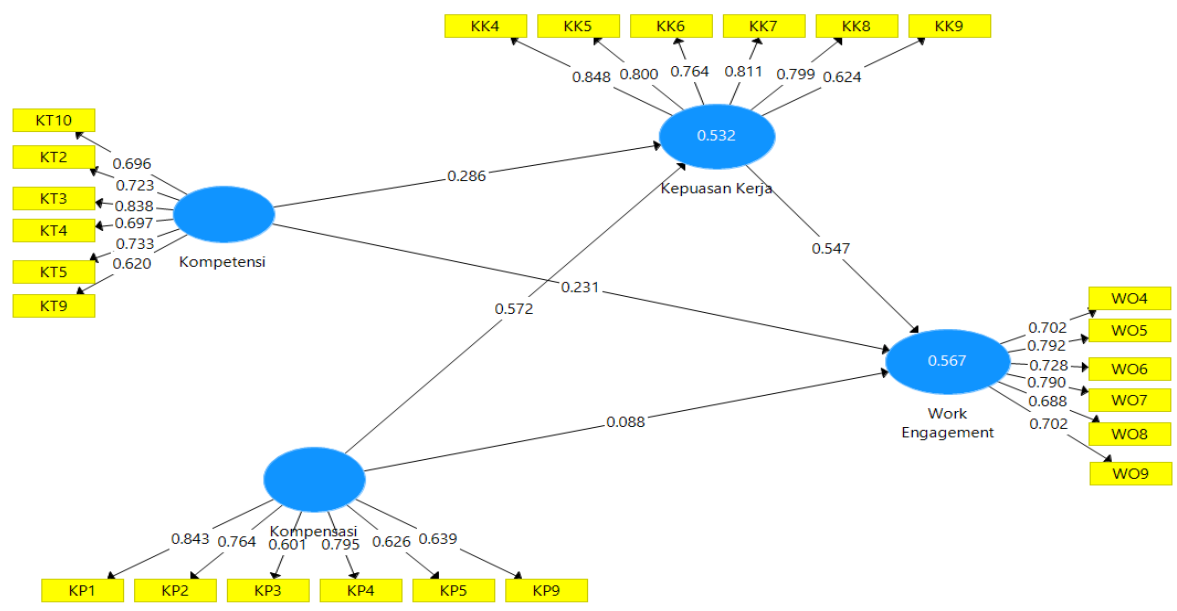

Gambar 3. Model SEM hasil revisi Sumber: Data diolah (2016) 
Berdasarkan Gambar 3, nilai loading factor sudah di atas 0,50. Maka model SEM yang terbentuk telah memenuhi convergent validity dan indikator-indikator tersebut telah merefleksikan konstruknya. Metode lain untuk mengevaluasi Convergent validity yaitu dengan melihat nilai Average Variance Extracted (AVE). Nilai AVE pada penelitian ini dapat dilihat pada Tabel 3 .

Tabel 3. Nilai AVE

\begin{tabular}{lccc}
\hline & AVE & Syarat Valid & Keterangan \\
\hline Kompetensi & 0,519 & 0,50 & Valid \\
Kompensasi & 0,515 & 0,50 & Valid \\
Kepuasan Kerja & 0,605 & 0,50 & Valid \\
Work Engagement & 0,540 & 0,50 & Valid \\
\hline
\end{tabular}

Sumber: Data diolah (2016)

\section{Discriminant Validity}

Discriminant validity dapat dilihat dari nilai cross loading. Nilai korelasi indikator terhadap konstruknya harus lebih besar dibandingkan nilai korelasi antara indikator dengan konstruk lainnya (Ghozali 2008).

Tabel 4. Hasil cross loading

\begin{tabular}{lcccc}
\hline Indikator & Kepuasan Kerja & Kompensasi & Kompetensi & $\begin{array}{c}\text { Work } \\
\text { Engagement }\end{array}$ \\
\hline KK4 & $\mathbf{0 , 8 4 8}$ & 0,676 & 0,277 & 0,588 \\
KK5 & $\mathbf{0 , 8 0 0}$ & 0,506 & 0,315 & 0,699 \\
KK6 & $\mathbf{0 , 7 6 4}$ & 0,560 & 0,525 & 0,583 \\
KK7 & $\mathbf{0 , 8 1 1}$ & 0,546 & 0,426 & 0,557 \\
KK8 & $\mathbf{0 , 7 9 9}$ & 0,426 & 0,413 & 0,501 \\
KK9 & $\mathbf{0 , 6 2 4}$ & 0,417 & 0,392 & 0,398 \\
KP1 & 0,578 & $\mathbf{0 , 8 4 3}$ & 0,241 & 0,430 \\
KP2 & 0,354 & $\mathbf{0 , 7 6 4}$ & 0,208 & 0,258 \\
KP3 & 0,389 & $\mathbf{0 , 6 0 1}$ & 0,192 & 0,331 \\
KP4 & 0,415 & $\mathbf{0 , 7 9 5}$ & 0,252 & 0,400 \\
KP5 & 0,393 & $\mathbf{0 , 6 2 6}$ & 0,179 & 0,335 \\
KP9 & 0,640 & $\mathbf{0 , 6 3 9}$ & 0,433 & 0,489 \\
KT10 & 0,280 & 0,151 & $\mathbf{0 , 6 9 6}$ & 0,318 \\
KT2 & 0,294 & 0,205 & $\mathbf{0 , 7 2 3}$ & 0,408 \\
\hline KT3 & 0,511 & 0,366 & $\mathbf{0 , 8 3 8}$ & 0,457 \\
KT4 & 0,396 & 0,368 & $\mathbf{0 , 6 9 7}$ & 0,474 \\
KT5 & 0,192 & 0,169 & $\mathbf{0 , 7 3 3}$ & 0,317 \\
KT9 & 0,382 & 0,259 & $\mathbf{0 , 6 2 0}$ & 0,281 \\
W04 & 0,497 & 0,290 & 0,487 & $\mathbf{0 , 7 0 2}$ \\
WO5 & 0,513 & 0,371 & 0,462 & $\mathbf{0 , 7 9 2}$ \\
WO6 & 0,525 & 0,487 & 0,372 & $\mathbf{0 , 7 2 8}$ \\
WO7 & 0,633 & 0,426 & 0,254 & $\mathbf{0 , 7 9 0}$ \\
W08 & 0,443 & 0,323 & 0,315 & $\mathbf{0 , 6 8 8}$ \\
W09 & 0,550 & 0,486 & 0,468 & $\mathbf{0 , 7 0 2}$ \\
\hline S69
\end{tabular}

Jurnal Manajemen dan Organisasi (JMO),

Sumber: Data diolah (2016)

Berdasarkan Tabel 4, dapat dilihat bahwa nilai cross loading masing-masing indikator terhadap konstruknya lebih besar dibandingkan nilai loading indikator dengan konstruk lainnya. Hal ini menunjukkan bahwa konstruk laten memprediksi indikator pada blok mereka lebih baik dibandingkan dengan indikator di blok lainnya. Semua indikator pada tabel di atas dinyatakan valid dalam pengujian discriminant validity ini. 
Uji Reliabilitas

Selain uji validitas konstruk, dilakukan juga uji reliabilitas konstruk yang diukur dengan dua kriteria yaitu composite reliability dan cronbach's alpha. Apabila hasil output composite reliability dan cronbach's alpha untuk semua konstruk di atas 0,70, konstruk dinyatakan reliabel (Ghozali 2008). Nilai composite reliability dan cronbach's alpha dapat dilihat pada Tabel 5.

Tabel 5.Composite reliability dan cronbach's alpha

\begin{tabular}{lcc}
\hline & Composite Reliability & Cronbach's Alpha \\
\hline Kompetensi & 0,865 & 0,814 \\
Kompensasi & 0,862 & 0,810 \\
Kepuasan Kerja & 0,901 & 0,868 \\
Work Engagement & 0,875 & 0,829 \\
\hline
\end{tabular}

Sumber: Data diolah (2016)

Tabel 5 menunjukkan bahwa semua konstruk memiliki composite reliability dan cronbach's alpha lebih dari 0,7, sehingga dapat disimpulkan bahwa semua konstruk telah reliabel.

Pengujian Model Konstruk

Selanjutnya yaitu evaluasi Model Struktural (Inner Model). Evaluasi Model Struktural (Inner Model) terdiri dari pengujian model konstruk dan uji hipotesis. Evaluasi inner model ini menggambarkan hubungan positif atau negatif antara konstruk endogen dan eksogen. Pengujian terhadap model struktural dilakukan dengan melihat nilai R-square. Data R-square dapat dilihat pada Tabel 6 .

Tabel 6. $R$-square

\begin{tabular}{lc}
\hline & R-square \\
\hline Kepuasan Kerja & 0,532 \\
Work Engagement & 0,567 \\
\hline Sumber: Data diolah (2016)
\end{tabular}

Sumber: Data diolah (2016)

Hasil pada Tabel 6 menunjukkan bahwa kepuasan kerja memiliki R-square sebesar 0,532 yang berarti bahwa konstruk kompetensi dan kompensasi mampu menjelaskan konstruk kepuasan kerja sebesar 53,2\% dan sisanya 46,8\% diterangkan oleh konstruk lain yang tidak dirumuskan dalam model. Sedangkan work engagement memiliki R-square sebesar 0,567 yang berarti bahwa kompetensi, kompensasi dan kepuasan kerja mampu menjelaskan konstruk work engagement sebesar 56,7\% dan sisanya 43,3\% diterangkan oleh konstruk lain yang tidak dirumuskan dalam model.

\section{Uji Hipotesis}

Selanjutnya uji hipotesis dilakukan untuk menjawab persamaan penelitian. Pengujian dan Manajemen hipotesis dapat dilihat dari nilai original sample dan nilai signifikansi T-statistik pada output path coefficient. Nilai T-statistik menunjukkan signifikansi konstruk, sedangkan nilai original sample menunjukkan sifat hubungan antar konstruk (positif atau negatif). Batas untuk menolak atau menerima hipotesis adalah nilai T-statistik 1,96 untuk $\mathrm{p}<0,05$ (two tailed). Berikut hasil path coefficient pada SmartPLS.

Tabel 7.Path coefficient

\begin{tabular}{lccc}
\hline & Original Sample & T-statistic & Hipotesis \\
\hline Kompetensi -> Work Engagement & 0.231 & 2.147 & Diterima \\
Kompetensi -> Kepuasan Kerja & 0.286 & 3.178 & Diterima \\
Kompensasi -> Kepuasan Kerja & 0.572 & 6.889 & Diterima \\
Kompensasi -> Work Engagement & 0.088 & 0.575 & Ditolak \\
Kepuasan Kerja -> Work Engagement & 0.547 & 3.668 & Diterima \\
\hline
\end{tabular}

Sumber: Data diolah (2016) 
Hasil pada Tabel 7 menunjukkan bahwa konstruk kompetensi berpengaruh signifikan terhadap konstruk kepuasan kerja karena nilai t-statistik $>1,96(3,178)$ dan juga berpengaruh signifikan terhadap konstruk work engagement dengan nilai t-statistik lebih dari 1,96 $(2,147)$. Artinya, semakin tinggi kompetensi karyawan UMKM kluster hasil pengolahan perikanan Kota Bogor maka akan meningkatkan kepuasan kerja pada karyawan itu sendiri. Para karyawan UMKM kluster hasil pengolahan perikanan Kota Bogor memiliki persepsi bahwa diri mereka terampil dalam melakukan pekerjaan. Karyawan memiliki persepsi bahwa pengetahuan yang mereka miliki mampu meningkatkan hasil kinerja atau produktivitas. Karyawan juga memiliki persepsi bahwa karyawan itu sendiri bertanggungjawab atas pekerjaan untuk mencapai hasil yang memuaskan. Karyawan yang kompeten akan merasa lebih puas dengan pekerjaan mereka. Selain itu, hasil ini berarti juga bahwa semakin tinggi kompetensi kerja pada karyawan UMKM kluster hasil pengolahan perikanan Kota Bogor maka akan meningkatkan work engagement pada karyawan itu sendiri. Mereka juga memiliki persepsi bahwa mereka senang saat mereka produktif dalam bekerja. Sehingga, pengetahuan yang mereka miliki membuat mereka lebih engaged dalam bekerja. Karyawan yang terampil dan mengetahui bagaimana mengerjakan pekerjaannya memang menunjukkan ciri-ciri bahwa ia fokus dalam bekerja. Selain itu, ia memiliki perasaan-perasaan yang positif tentang pekerjaannya. Sehingga ia dapat menunjukkan pencapaian yang baik dalam pekerjaannya yang menunjukkan kepuasan kerjanya. Contohnya yaitu ia bisa menghasilkan cukup banyak produk. Hasil ini didukung oleh penelitian Dhermawan et al. (2012) yang menunjukkan bahwa kompetensi berpengaruh secara signifikan terhadap kepuasan kerjapada pegawai Kantor Dinas Pekerjaan Umum Provinsi Bali yang menjadi responden. Selain itu, hasil ini sesuai dengan teori yang menyatakan bahwa kompetensi meningkatkan engagement dalam mengerjakan pekerjaan (Gagné 2014).

Konstruk kompensasi tidak berpengaruh signifikan terhadap konstruk work engagement karena nilai T-statistik kurang dari $1,96(0,575)$, namun berpengaruh signifikan terhadap konstruk kepuasan kerja dengan nilai T-statistik lebih dari 1,96 (6,889). Artinya semakin tinggi kompensasi karyawan UMKM kluster hasil pengolahan perikanan Kota Bogor maka kepuasan kerja karyawan itu sendiri akan meningkat. Kompensasi tidak berpengaruh terhadap work engagement, tetapi sebaiknya kompensasi tetap perlu diperhatikan walaupun hanya memberikan kontribusi yang kecil. Karyawan UMKM kluster hasil pengolahan perikanan Kota Bogor memang masih banyak yang mendapatkan kompensasi yang belum mencukupi. Sebagian besar kompensasi yang diterima masih di bawah UMR. Kompensasi yang dirasa kurang oleh karyawan menjadi alasan mengapa sebagian dari mereka keluar dari UMKM dan bekerja di tempat lain. Selain itu, sebagian UMKM hanyalah merupakan usaha sampingan bagi pemiliknya dan hanya berproduksi apabila ada pesanan. Hal ini menyebabkan kompensasi yang diterima oleh karyawan menjadi tidak menentu, baik jumlahnya maupun waktu penerimaannya. Tidak adanya jenjang karir juga perlu diperhatikan. Karyawan tidak mengetahui apakah karir mereka dapat berkembang di UMKM tersebut. Hal-hal ini menunjukkan bahwa kemungkinan kompensasi tidak berpengaruh terhadap work engagement karena tingkat kompensasi yang ada di UMKM kluster hasil pengolahan perikanan di Bogor belum memadai untuk membangun work engagement karyawannya. Hasil ini didukung oleh penelitian Karyawati (2014) yang menunjukkan bahwa kompensasi berpengaruh secara signifikan terhadap kepuasan kerja pada UKM Batik Bogor Tradisiku.

Konstruk kepuasan kerja berpengaruh signifikan terhadap konstruk work engagement karena nilai T-statistik lebih dari 1,96 (3,668). Artinya semakin tinggi kepuasan kerja karyawan UMKM kluster hasil pengolahan perikanan Kota Bogor maka akan meningkatkan work engagement pada karyawan itu sendiri. Karyawan yang puas dengan pekerjaannya memiliki perasaan-perasaan yang positif mengenai pekerjaannya. Karyawan memiliki persepsi bahwa kesesuaian kompensasi yang mereka dapatkan, tugas yang mereka dapat untuk dilaksanakan serta lingkungan beserta fasilitas yang ada pada UMKM tempat mereka bekerja mempengaruhi kepuasan kerja mereka. Jika diamati, karyawan yang sudah puas dengan hal-hal tersebut memang lebih engaged dalam bekerja. Karyawan yang mendapatkan kompensasi yang baik bisa lebih engaged dalam bekerja. Hal ini dikarenakan kompensasi yang semakin tinggi menuntut 
seorang karyawan untuk bekerja dengan lebih fokus untuk menghasilkan yang lebih baik. Selain itu, apabila mereka menguasai tugas yang mereka dapatkan, mereka menjadi lebih engaged dalam bekerja, seperti hasil di atas yang menyebutkan bahwa kompetensi mempengaruhi work engagement karyawan. Selanjutnya, lingkungan kerja yang baik juga membuat para karyawan lebih engaged. Contohnya, pada saat para karyawan memiliki hubungan kerja yang baik. Karyawan menjadi lebih bersemangat dalam bekerja. Fasilitas kerja juga mempengaruhi engagement. Fasilitas kerja yang dimiliki oleh UMKM rata-rata sudah baik sehingga karyawan dapat lebih fokus dalam mengerjakan pekerjaannya. Sebab, fasilitas kerja yang lebih baik memudahkan bagi karyawan untuk berkonsentrasi dalam bekerja. Karyawan dengan tenang mengerjakan pekerjaannya saat peralatan yang diperlukan sudah ada dan layak pakai. Hal ini sesuai dengan penelitian Kari (2013) yang menunjukkan bahwa kepuasan kerja berpengaruh signifikan terhadap engagement karyawan administratif Politeknik Negeri Bandung.

\section{KESIMPULAN}

Persepsi karyawan UKM kluster pengolahan hasil perikanan Kota Bogor terhadap indikator-indikator kompetensi, kompensasi, kepuasan kerja dan work engagement mayoritas menunjukkan pendapat setuju dan dapat dikategorikan baik. Hasil analisis SEM menunjukkan bahwa kompetensi dan kompensasi berpengaruh terhadap kepuasan kerja karyawan. Hal ini berarti bahwa semakin tinggi tingkat kompetensi karyawan dan tingkat kompensasi yang diterima karyawan UMKM kluster hasil pengolahan perikanan Kota Bogor maka semakin tinggi juga tingkat kepuasan kerja karyawan tersebut.

Analisis SEM menunjukkan pula bahwa kompetensi dan kepuasan kerja berpengaruh terhadap work engagement. Hal ini berarti bahwa semakin tinggi tingkat kompetensi dan kepuasan kerja karyawan UMKM kluster hasil pengolahan perikanan Kota Bogor maka semakin tinggi juga tingkat work engagement karyawan tersebut. Kompensasi tidak berpengaruh terhadap work engagement. Hal ini berarti bahwa semakin baik tingkat kompensasi yang diterima karyawan UMKM kluster hasil pengolahan perikanan Kota Bogor maka tidak terjadi peningkatan work engagement pada karyawan tersebut. Hal ini juga berarti bahwa kemungkinan tingkat kompensasi yang ada di UMKM kluster hasil pengolahan perikanan Kota Bogor belum memadai untuk membangun work engagement karyawannya.

\section{DAFTAR PUSTAKA}

Dessler G. 2010. Manajemen Sumber Daya Manusia. Rahayu P, penerjemah; Hardiansjah FH, editor. Jakarta (ID): INDEKS. Terjemahan dari: Human Resource Management Ed ke-10.

Jurnal Manajemen dan Organisasi (JMO), Vol. 9, No. 1, April 2018, Hal. 10-21
Dhermawan AAN, Sudibya IGA, Utama IWM. 2012. Pengaruh Motivasi, Lingkungan Kerja, Kompetensi dan Kompensasi Terhadap Kepuasan Kerja dan Kinerja Pegawai di Lingkungan Kantor Dinas Pekerjaan Umum Provinsi Bali. Jurnal Manajemen, Strategi, Bisnis dan Kewirausahaan. 6(2):173-184.

Dinas Koperasi dan Usaha Kecil Menengah Provinsi Jawa Barat. 2013. Pemberdayaan KUMKM Jawa Barat dalam Menghadapi Masyarakat Ekonomi ASEAN 2015 [Internet]. [diunduh 2016 Agustus 26]. Tersedia pada: http://www.depkop.go.id/.

Dinas Koperasi dan UMKM Kota Bogor. 2016. Pertumbuhan UMKM Kota Bogor Tahun 20112015. Bogor (ID): Dinas Koperasi dan UMKM Kota Bogor.

Gagné M. 2014. The Oxford Handbook of Work Engagement, Motivation, and SelfDetermination Theory. New York (US): Oxford University Press.

Ghozali I. 2008. Structural Equation Modeling Metode Alternatif dengan Partial Least Square (PLS). Jakarta (ID): Badan Penerbit Undip.

Gryseels M, Manuel N, Salazar L, Wibowo P. 2015. Ten ideas to maximize the socioeconomic impact of ICT in Indonesia [internet]. [diunduh pada 2016 Februari 8]. Tersedia pada: http://www.mckinsey.com.

Hutapea P, Thoha N. 2008. Kompetensi Plus. Jakarta (ID): Gramedia Pustaka Utama. 
Kadarisman M. 2012. Manajemen Kompensasi. Jakarta (ID): Rajawali Pers.

Kari A. 2013. The Effect of Job Satisfaction and Motivation on Employee Engagement of Administrative Staff of Bandung State Polytechnic. Jurnal Ilmu Manajemen \& Bisnis. $4(1)$.

Karyawati E. 2014. Pengaruh Kompensasi terhadap Kepuasan dan Kinerja Karyawan UKM Batik Bogor Tradisiku [skripsi]. Bogor (ID): Institut Pertanian Bogor.

[Kemenkop] Kementerian Koperasi dan Usaha Kecil dan Menengah. 2015. Laporan Tahunan Kementerian Koperasi dan Usaha Kecil dan Menengah [internet]. [diunduh 2016 Agustus 26]. Tersedia pada: http://www.depkop.go.id/.

[Kemenkop] Kementerian Koperasi Dan Usaha Kecil Dan Menengah. 2015. Rencana Strategis (Renstra) Kementerian Koperasi dan Usaha Kecil dan Menengah Tahun 2015-2019 [internet]. [diunduh 2016 Agustus 26]. Tersedia pada: http://www.depkop.go.id/.

[OJK] Otoritas Jasa Keuangan. 2016. Siaran Pers: Dorong Pengembangan UMKM OJK Gandeng Kementerian Koperasi [internet]. [diunduh 2016 Agustus 26]. Tersedia pada: http://www.ojk.go.id/.

Pemerintah Provinsi Jawa Barat. 2014. Kontribusi Jawa Barat Terhadap Nasional [internet]. [diunduh 2016 Agustus 26]. Tersedia pada: http://jabarprov.go.id/infografis/.

Rahmawati L. 2014. Konsumsi ikan warga Kota Bogor sangat rendah [internet]. [diunduh 2017 Januari 26]. Tersedia pada: http://megapolitan.antaranews.com.

Rivai V, Sagala E. 2009. Manajemen Sumber Daya Manusia untuk Perusahaan: dari Teori ke Praktik. Jakarta (ID): Rajawali Pers.

Saks AM, Gruman JA. 2014. What Do We Really Know About Employee Engagement? Human Resource Development Quarterly. 25(2):155-182.

Schaufeli W, Bakker A, Salanova M. 2006. The Measurement of Work Engagement With a Short Questionnaire: A Cross-National Study. Educational and Psychological Measurement. 66(4):701-716.

Schaufeli W, Salanova M. 2011. Work engagement: On how to better catch a slippery concept. European Journal of Work and Organizational Psychology. 20(1):39-46.

Simamora H. 2004. Manajemen Sumber Daya Manusia Edisi 3. Yogyakarta (ID): Bagian Penerbitan Sekolah Tinggi Ilmu Ekonomi YKPN.

Umar H. 2013. Desain Penelitian MSDM dan Perilaku Karyawan: Paradigma Positivistik dan Berbasis Pemecahan Masalah. Jakarta (ID): Rajawali Pers.

Wiyono G. 2011. Merancang Penelitian Bisnis dengan Alat Analisis SPSS 17.0 \& SmartPLS 2.0. Yogyakarta (ID): CV Andi. 